\title{
Exit the polibation officer? Decoupling police and probation
}

\author{
Mike Nash \\ Institute of Criminal Justice Studies, University of Portsmouth, Ravelin House, Museum \\ Road, Portsmouth, PO1 2QQ, UK. Email: mike.nash@port.ac.uk
}

Received 2 May 2007; accepted 30 June 2007

Keywords: probation, probation officers, policing, UK criminal justice

Mike Nash is Reader in Criminology and Head of Department at the Institute of Criminal Justice Studies, University of Portsmouth. A former probation officer, he has published widely on issues connected with the probation service and prisons in the UK.

\begin{abstract}
Since 1999 the pages of this journal have periodically carried articles based on the idea of a 'polibation' officer, or variants on that theme. The idea arose from the possible outcomes of increasingly closer collaboration between police and probation services under the public protection umbrella. Eight years on it is evident that, in a variety of settings, roles have been established which take individual practitioners some way from their roots in terms of professional practice and culture. This article briefly revisits this process and explores the pros and cons of fused roles. It concludes with the announcement of a split in the functions of the Home Office which results, at least on paper, in a decoupling of police and probation services. The future of the polibation officer is considered in this light.
\end{abstract}

\section{BACKGROUND}

Back in 1999 I wrote about an emerging phenomenon, a fusion of police and probaInternational Journal of Police Vol. 10 No. 3, 2008, pp. 302-312. DOI: $10.1350 /$ ijps.2008.10.3.86 tion roles into one entity, the 'polibation officer' (Nash, 1999). This invention was in response to the growing multi-agency agenda for public protection and in particular the possible effect of closer collaboration between the two services on their 'traditional' roles. At the time I was concerned that probation officers in particular would lose their focus on what was considered to be a welfare or humanitarian approach, one of their traditional contributions to criminal justice. My reason for this was that the nature of the public protection agenda itself, which appeared to be geared more towards control and surveillance, would radically shift probation staff away from their focus on the welfare aspects of supervising offenders in the community. The polibation officer would become, I believed, the epitome of the government's determination to 'join-up' justice. The argument was that this was not, de facto, a bad idea, more that it could have considerable cultural implications for the organisations involved. These will be reviewed briefly below and brought up to date. However, they will culminate in a discussion of an announcement by the then Prime Minister, Tony Blair, on 29 March 2007, to split the functions of the Home Office, with policing remaining in the Home Office (more heavily focused upon security) and the new Ministry of Justice formed of the remaining Home Office 
functions and the Department for Constitutional Affairs. It is within this context that I wish to consider the future of the polibation officer, whilst recognising other threats to what was an imagined concept which has become a reality, to greater or lesser extent, in much of the country.

Multi-agency working does not of course just concern itself with two agencies, the police and probation services. Depending upon the issue to be tackled, a variety of constituents will come together with a common purpose, for example child protection. The rationale is clear and in most respects above criticism. It is almost certainly the case that any social issue will involve more than one agency; for example health, housing, education, police, social services and possibly probation and prisons in a child protection matter. The overriding intention here is to ensure that full communication exists between agencies involved, that vital information is given, received and acted upon and that ongoing reviews also share as much as possible. The intention is clearly to break down agency barriers and ensure that professional jealousies and territory-guarding do not get in the way of saving the life of another person. However, there is another very important aspect of multi-agency working and the clue is in its name. It is meant to be the combined knowledge and abilities of a range of relevant agencies brought together on one issue. In other words, the whole is stronger than its constituent parts but its strength arises from its constituent parts. It is the coming together of a variety of perspectives on one issue that is important, rather than the elaboration of one view. It was precisely in this area that police and probation officers began to work much more closely together at the beginning to mid 1990s and by the end of the decade were, in my view, in danger of fusing within the area of public protection. Let us reconsider this agenda for a moment.

\section{THE EMERGENCE OF THE PUBLIC PROTECTION AGENDA}

Throughout the 1990s the public protection agenda was rapidly growing in political importance. Although a few well-publicised cases attracted public and media attention, it was the battle between Conservative and Labour politicians that perhaps really elevated it to a position of dominating not only criminal justice debate, but also policy and practice. The increasingly unpopular Conservative Governments, gradually seeing their electoral majorities eroded, were desperate by the mid 1990s, to find something to distance them from the resurgent Labour party. In a sense perhaps they believed they had found the perfect combination in law and order policy (an old Tory favourite and weakness for Labour), a political bruiser (Michael Howard as Home Secretary) and the British public's love for 'things American' (the tough policies of Ronald Reagan and, later, Bill Clinton). The importation of American ideas was intended to 'smoke out' the 'wets' in the Labour Party, and bring to the surface the socialist credentials that it seemed increasingly to wish to cover over. The battleground gradually became that of public protection, personified by the predatory sex offender, and particularly by the predatory paedophile. There appeared to be a clear attempt by the Conservative Government, with Michael Howard in the vanguard, to push the members of the Opposition so far that they would eventually have to resist or object. As the chosen battleground had become the protection of 'innocence', this would have been a set-and-match victory for the Conservatives. In fact the Labour Party did not take the bait but under its bright and ambitious shadow Home Secretary, Tony Blair, began to raise the stakes. It accepted almost everything that was thrown into the pot and adopted a policy of not publicly opposing the Conservative 
measures. As a result, public protection ceased to be a political issue and quite simply emerged into policies that were not really debated. It was within this political battle and eventual settlement that the ground for significant changes in police and probation practice was laid out and led to the title of my earlier article.

The salient themes of this early public protection agenda were focused on punishment, disproportionality in sentencing, 'extra' punishment for certain offenders and increased control and surveillance in the community underpinned by greater collaboration between the police and probation services. An early scene-setting example had been contained in the Criminal Justice Act (CJA) 1991. In an Act strongly reflecting the principle of proportionality in sentencing (ostensibly in order to reduce the prison population which then stood at 48,000 ), an opportunity to sentence outside this principle was introduced. In the case of violent and sexual offenders provision was made to depart from proportionality in imposing custody where not warranted by the instant offence (public protection), imposing sentences up to their maximum when not warranted by seriousness, or by using previous convictions where they revealed a pattern of negative behaviour. The 1990s also witnessed the introduction of mandatory minimum penalties and also mandatory life sentences in certain cases. The latter were a variant of the US 'three strikes and you're out' policy set by Ronald Reagan. Add to this the introduction of sex offender registration, introduced in the Sex Offenders Act (SOA) 1997, and it was clear that a general toughening and hardening of the criminal justice process was under way. Beneath these outwardly harsher policies were perhaps more subtle changes to the nature and philosophy of probation working, themselves a reflection of these new measures but also perhaps in part as much an attempt by the probation service to survive.

It is evident that in this tough, competitive law and order world, the idea of being 'alongside the offender', and committed to his welfare, would not hold a great deal of water. Despite a continued residue of support in the House of Lords for traditional probation values, the Commons saw a quite different attitude emerging. Here it was to be who could be toughest on crime that would win. As noted above, the CJA 1991 had already set the tone by introducing the idea of punishment in the community and restriction of liberty. The long-standing principle of probation disposals being regarded as an alternative to a sentence was abandoned in favour of making them community punishments in themselves. During a period where it appeared as if increasing the size of the prison population was the thing to do, the probation service can be thankful for the cautionary note struck by the Treasury, which alluded to the huge cost of mass imprisonment and what this would do with (Conservative) Government promises to cut taxes. The philosophy of bifurcation (Bottoms, 1977) and later 'punitive bifurcation' (Cavadino \& Dignan, 1997) was therefore established whereby dangerous offenders (sexual and violent crimes predominantly) would receive harsher sentencing, but nondangerous offenders would be sentenced to punishment in the community, a controlled and restricted version of the old probation order, underwritten and enforced by new national standards of supervision, compliance and enforcement. Thus, in an era when it looked as if the writing was on the wall for the probation service, there was an escape route identified, if it was prepared to take on the new tough mantle of community punishment. It did so; some might argue with gusto (ACOP,1988) and began to reposition itself successfully as a public protection agency as the decade wore on. From 
the mid 1990s, police and probation services began to collaborate informally on work with potentially dangerous offenders (Kemshall \& Maguire, 2001; Nash, 1999) and, with the introduction of the Criminal Justice and Court Services Act 2000, this process was elaborated and became a formal requirement for police and probation (the latter added to by the prison service in the Criminal Justice Act 2003) as responsible authorities. Thus it could be argued that this collaboration, which I argued led to the emergence of a polibation officer, was a product of tough times and brought together two unlikely bedfellows. For the probation service it hinted at organisational survival when its future, at least for a time, looked in doubt. For the police service it offered the chance to utilise the expertise of another agency in its new responsibilities for sex offenders in the community under the Sex Offenders Act 1997. It also, of course, built upon best practice in child protection cases and also on the increasing multi-agency collaboration over mental health cases.

\section{MULTI OR MONO?}

At issue therefore, at least for some commentators, was the impact this agenda would have upon the ways of working, or perhaps more accurately, the organisational culture of the separate agencies involved. In other words, would the strength of various perspectives coming together on one issue be replaced by a more homogenised view arising from joint protocols and agreed decisions? The coming together was also very specific in that it was a child of its time and heavily politicised from the off. The agenda had been set to protect the most vulnerable from the most awful and thus had a proactive impetus that would soon, according to a number of commentators, drift into additional punishment, or permanent 'marking' and exclusion (Garland,
2001). It was this sense of where the process might be heading that suggested the idea of the polibation officer to me, and had led Kemshall and Maguire (2001) to describe the 'policification' of probation as they saw it. The rationale behind these ideas was that the very nature of the agenda just briefly described was a controlling, enforcing and potentially punitive one. As such it somewhat conflicted with the traditional values, and ways of working, long held by the probation service and described by Vanstone (2004) as 'humanitarian'. The new agenda was greatly concerned with assessing and managing risk, tasks that would grow into a 'big business' (Kemshall, 2003). But hidden within this agenda, perhaps, was the increasing reconceptualisation of problems or need into risk, thus transforming the way in which probation officers would routinely deal with offender difficulties. As Kemshall (p. 1) notes, risk assessment and management has 'replaced the traditional rehabilitative focus'. Now of course the best outcome of multi-agency working is not only to ease communication but to share perspectives and experiences. In other words, agencies which work with offenders in their communities, with experiences of family dynamics and the effects of a range of personal and social problems, may see the world quite differently from a person concerned with preventing or detecting crime. Both positions are perfectly valid and both contribute fully to the way in which offenders can be safely managed in communities. But, if an agenda begins to raise the profile of one of these aspects, and another becomes unfashionable or offmessage, the variety of perspectives becomes muddled.

Thus commentators such as Kemshall and Maguire (2001) and Nash (1999) began to wonder if there would be an impact on the culture of the organisations concerned, and if one culture would begin to dominate another. Because the public protection 
message was so strong, and one which was traditionally associated with police activity, there was a feeling that probation might 'go the way of the police'. However, it should be clear that public protection was not the sole driver at this time. It has already been noted that organisational survival was an issue for the probation service after 1979 and throughout the 1990s a fair amount of positioning had been undertaken from within and without. Thus the probation service had been keen to state its credentials as a credible criminal justice agency for modern day penal policies. It was prepared to accept that much of the philanthropic ideal had dissipated since its inception at the beginning of the nineteenth century and its ethos needed a makeover. The police also needed to shift their position. As a result of a number of high profile cases and incidents, they had sought to increase their community engagement and work with other agencies: see Wright (2000, pp. 288-9) for a summary of incidents. For our purposes, the emerging public protection agenda served both intentions admirably. For the probation service, the opportunity to get alongside the police would undoubtedly, in some quarters, enhance its credibility as a law and order agency. For the police it would formally involve them in a multiagency forum that matched their crime control and management intentions, but also afforded them the chance to work with others on new roles such as taking responsibility for sex offenders in the community. Thus this new agenda offered several opportunities at different levels. There was the prospect of enhancing the rebranding of probation and also the development of a role for the police which was increasingly epitomised by multi-agency collaboration. There was also the prospect, however, of agencies becoming more like each other and thus becoming indistinct, or of agencies actually changing to become more like their stronger partners, thereby losing their individual traditions and assuming others. This was the point at which the 'polibation officer' debate began.

\section{THE FUSION OF ROLES?}

As noted above, some of the early comments on this issue hinted that the probation service was the most likely to change and both Nash (1999) and Kemshall and Maguire (2001) coined terms to describe this process. Further variations on this theme can be found in Mawby and Worrall (2004), Nash (2004) and Mawby, Crawley and Wright (2007). Both the polibation concept, and 'policification', came as a result of not only reading between the lines, but actual observance of the embryonic multi-agency public protection arrangements (MAPPA). As indicated above, the new mood surrounding public protection was very much a controlling and enforcing one, with the assessment and management of risk as the primary driver. Probation staff, in particular, could be seen to be moving towards new territory. A much stronger emphasis on control and restriction, with needs becoming redefined as risks, meant that a traditional focus upon offender 'welfare', even if maintained, would be constructed within a quite different climate. For the police service, however, the notion of surveillance and restraining measures was familiar territory, and it was not too difficult to foresee the influence they might bring to bear upon multiagency proceedings. At the same time they might well have been looking for assistance with new-found responsibilities such as those for sex offenders in the community. This was therefore a forum where two key criminal justice players both had something to gain from closer collaboration. In some sense the new agenda was slightly different from child protection conferences, in that agencies perhaps shared roles and goals in a more focused manner. Child protection, 
although always a high-profile issue, did perhaps remain principally a social services 'problem'. Public protection, from the off, was a shared responsibility and as such individual agency perspectives perhaps merged more readily than in previous multi-agency fora. More than that, however, was the very strong central direction concerning how this process should be managed and conducted. The issue therefore was whether MAPPA would be the sum of its individual but different parts or the sum of increasingly similar parts. At the heart of this issue lies a question of what multi-agency working should really mean.

In commenting on multi-agency work with young offenders, Sheldrick (1999) notes that the strength of having a variety of agencies involved in assessment is a variety of perspectives and those individual professionals should stick to the limits of their expertise. If, however, agencies increasingly share the public protection party line, then this difference may be compromised. As such this process might be thought of in these terms: probation officers are, in many ways, doing a job they have always done but, for a variety of reasons, seeking to do it differently. The police however are undertaking in a sense new responsibilities but perhaps within the same monitoring and surveillance mandate. There is therefore something of a natural coming together of these two roles and the issue becomes one of who changes the most?

It may, however, be more than simply the process of closer collaboration that is impacting upon individual agency practice. It could be that the sheer scale of the public protection process, its centrality to political debate and constant interest for the media, has a greater impact. In other words the spectacular increase in both numbers of offenders and bureaucracy of the process determine a different way of working. Let us consider one aspect of this. There are at present over 46,000 MAPPA offenders in the community. Approximately 12,500 are assessed as level 2 (local inter-agency management) and nearly 1,230 as level 3 (senior multi-agency oversight) (Scott, Grange, \& Robson, 2007). Although much of the activity may therefore be a risk filtering process, it still requires huge resources to make those decisions. These decisions are, however, high risk in themselves and there is a growing awareness of risk aversion and defensive practice in a number of agencies. The parole board has, it appears, become more cautious in its release decisions for certain categories of prisoners. From April to September 2006, out of 901 requests for lifer release only 106 were granted, the ratio typically being $1: 5$ previously (BBC, 2006). In its 2005-6 annual report, the chairman of the parole board, Sir Duncan Nichol stated, 'we will be absolutely sure before we release' (Parole Board for England and Wales, 2006). Aside from the impossibility of being absolutely sure, this statement implies that risk-taking by the board will very much reduce in the near future. In another example, in a recent discussion with a probation officer, she spoke of her despair at the prison service marking all files 'high risk' rather than take the chance of getting a decision wrong. Elsewhere I have written about the importance of really getting to know offenders if high-risk assessment and management is to mean anything (Nash, 2006). However, anecdotal discussion suggests that time is the one resource no longer available to criminal justice staff as throughput and completion targets dominate and, more importantly, determine funding levels.

High risk is a construct. It is determined by government in particular but also to a great extent by what the media perceive a dangerous person to be. This continues to be fixed on matters such as predatory and stranger assault, despite the continuing evidence that it is familial assault which leads to a far greater number of (vulnerable) 
victims - and even features very highly in a large number of politically sensitive serious further offence cases. Corrigan (2006) has written about how sex offender registration in New Jersey (Megan Kanka's home state) tends to exclude virtually all familial or acquaintance abusers. This is because they mostly score zero on the risk scale and thus are outside registration requirements. The strength of MAPPA arrangements should precisely be to bring knowledge of similar scenarios, and patterns of offending behaviour, to the table for discussion. More importantly perhaps, they should be a platform for lobbying government over what could be argued is a runaway public protection train. Yet, as agencies become more similar in their approach to public protection (or say it is not their responsibility), so the knowledge base for such interventions decreases.

According to the government, public protection arrangements are working very well, not least when the low number of serious further offences committed by those deemed to present the highest risk is so low (20 per cent of all such offences). Yet this does mean that 80 per cent of all serious further offences are committed by people assessed as low to medium risk and thus falling outside the MAPPA processes. What does this really tell us? On paper, high-risk offender supervision is working well. But, as ever with dangerousness, no one knows if these offenders operating at the top end of the offending spectrum would have reoffended in a serious manner. Historically the reconviction rate for released life sentence prisoners is low (less than 4 per cent for 'grave' offences; see Kershaw, Dowdeswell, \& Goodman, 1997) so it is perhaps precipitate to argue that the arrangements work, because no one knows if they actually needed to work. This is not as crass as it may appear. By delineating offenders into risk categories the temptation will always be to push people up rather than down (although resources may eventually force a reversal). Implicit also is the notion that high risk and very high risk must be 'exceptional' so everyday violence and sexual assault becomes downgraded. But isn't it these very people who are going on to offend again in a serious manner? The government's current proposal for contestability in the probation service (Home Office, 2006a, 2006b) appears to suggest that work with many of these lower-risk offenders can be carried out by other agencies: they do not require the skills of fully trained probation staff. Yet it is these offenders who may be posing the most problems of repeat offending behaviour and escalation to more serious offending.

The polibation officer was an idea; a view of how one agenda might impact upon individual agency practice. It is evident, however, that there are people fulfilling this role working in public protection teams, or polibation teams. They will however focus on the top end of offenders in a very bureaucratically prescribed manner. The very nature of the response to these offenders is likely to focus on tightly packaged risk assessment with little scope for leeway. The 'risks' probation officers once took with such offenders (with seemingly little serious fallout) are perhaps now a risk too far. But it was that risk-taking that enabled probation officers to make their distinct contribution to criminal justice, develop their skills at working with highrisk individuals and get to know them. The evidence suggest this is increasingly less the case and it becomes difficult not to view this as a deskilling exercise at the very time when the government lauds the high levels of skill and expertise in the MAPPA processes. At the same time, these (perhaps diminishing) skills are lost on working with lower risk offenders and indeed, it may be the case that these offenders are increasingly supervised by practitioners with lower level and more generic skills and knowledge. 
Working with high risk should inform working with low risk - this is how signs of escalation might be recognised. By artificially splitting practice along risk categories (which should in every case be a continuum anyway (Bridges, 2006)), vital knowledge and experience will be absent from large sections of probation supervision practice.

Has the advent of the polibation officer hastened this process? My feeling is that it has. The polibation officer has become the embodiment of a process which has bureaucratised and pigeonholed risk. Understanding the vagaries of human behaviour and the distinctiveness of their actions, which made Prins (1988) suggest that there were only 300 to 400 truly dangerous people in the country, appears to be increasingly squeezed out of everyday practice. People skills are required less than an ability to construct and monitor a plan based upon bureaucratically derived risk indicators, which, as noted earlier by Corrigan (2006), may omit significant numbers of potentially dangerous people. It is worrying if there is an assumption abroad that risk is something to be managed without really knowing as much as possible about the offender and his history (Madden, 2007, pp. 64-8).

'Polibation officer' is thus a fanciful name for what has become in reality a public protection officer, who may be a police or probation officer and occasionally a prison officer. There has not only been closer collaboration but there have been actual secondments and appointments to multidisciplinary teams. Public protection has grown exponentially and, partly as a result of this, the government plans to replace probation officers with others to work with lower-risk offenders. This is likely to continue to erode much of the traditional welfare (or 'humanitarian'; see Vanstone, 2004) culture of the probation service. This work will be carried out by people 'better suited' and thus obviate the need for this approach from probation officers who will increasingly focus on risk management (minus a welfare approach). This could be the nail in the coffin of probation officer distinctiveness. At a time when the service is celebrating its centenary, many of its traditions are being cut off at the roots. This is not, however, a nostalgic call for a return to probation 'values'. It is a reaffirmation of the application of this approach to public protection. The philosophy behind not adopting a 'welfare' approach to public protection appears to be concerned with it being too offender focused, with a greater emphasis on offenders' rights above those of the public (HMIP, 2006). This is a flawed idea. A welfare approach was not about making life better for offenders by providing counselling and practical assistance: it was this but linked to their offending behaviour. It was a welfare approach linked with the causes of crime and, in some cases, if these causes were ameliorated, the risk of further crime was lessened. It is also not to say that officers raised in a welfare tradition could not exercise control and restraints in the community, or have an understanding of victims' feelings. By excluding this approach and relying increasingly upon the control of risks, whole aspects of human behaviour, in its infinite variety, are reduced to paper-based risk classifications. This may be the worst outcome of the polibation process.

\section{BACK TO SQUARE ONE?}

The plans to split the functions of the Home Office, already noted in this article, will, at least in terms of Ministerial responsibility, shift lines of accountability of police and probation staff. The underlying message in the proposals is government concern with the big issues of the day: terrorism and immigration. Where will public protection from high-risk offenders fit with this new world? It is evident that 
hi-tech solutions are increasingly seen as the way to respond to these risks (for example, the possibility of compulsory lie detection tests and satellite tracking of offenders). These measures have even been supported by organisations such as Barnardo's (2006). The adoption of some of these measures with high-risk offenders (sexual offenders in particular) has in part hastened the decline of the welfare approach and reconfigured probation officers as part of the control process. Examples might be the administration of drug tests alongside a remarkably strict enforcement policy. Will the location of the probation service in a Ministry of Justice alter this ethos? This takes us back almost to crystal ball time.

A new Ministry with an emphasis on the work of the courts, prisons and probation, all of which have a stake in, and are very much feeling, the impact of public protection measures, may feel able to formulate counterarguments to the prevailing political orthodoxy. However, there has already been a lively debate concerning the split and some commentators have doubted that there will be any significant benefit. For example, Ken Jones was reported in The Independent on 20 April 2007, as saying that it would be harder for the police to work with others in the criminal justice system. $\mathrm{He}$ said, '. . . intelligence-gathering and supervising dangerous offenders rely on all criminal justice agencies working in partnership, and separating them into two ministries mean that we will have to work much harder to ensure that the strong partnerships that have been built up continue to develop' (Bentley, 2007). Concern has been expressed over the independence of the judiciary and the possible compromising of legal resources in a Ministry with prisons as a major competitor (Rozenberg, 2007). The government is clear that public protection remains a priority for both Home Office and Ministry of Justice and, as if to underline this, says that the 'Home Secretary will continue to have a core role in decision-making in this area' (Cabinet Office, 2007a). However, it is not difficult to see the potential tensions of departments which remain concerned about overcrowding (prison service), the extended use of public protection sentences (prison and probation services), the involvement of Ministers in sentencing decisions (the judiciary) and sentencing becoming restricted by resource issues elsewhere in the system. There are also tensions to be seen in other aspects of the government's proposals. For example, the security, crime and justice strand of the government's Policy Review (Cabinet Office, 2007b, p. 9) suggests that 'personalised case management [will be] a reality for all offenders and bring a renewed focus to serially prolific offenders'. Elsewhere in the document this is described as 'targeting the offender, not the offence' (p. 26). Yet, elsewhere the push for greater efficiency is epitomised by the government's quest for 'contestability' (see the Offender Management Act 2007) for the probation service and the desire for the service to use a range of high-quality service providers to work with offenders. How does this really help getting to know the offender, such a crucial component of working with dangerousness?

Lord Falconer, the first head of the Ministry of Justice stated, 'There is one reason, and one reason alone, why we need the Ministry of Justice: to improve the justice system for the people of this country' (Mitchell, 2007). Such a grand statement can encompass many aims, some of which will undoubtedly be in conflict. In commenting on the proposals, the Director of the Prison Reform Trust, Juliet Lyon, said the new Ministry, 'could mark the start of a fairer, more balanced criminal justice system with a return to proportionality and fairness in sentencing, a probation service 
valued for careful casework and management of risk, and prisons back where they belong as places of last resort' (Tempest, 2007). Thus there is a diversity of opinion where the new Ministry might position itself. There is already concern that courts will lose funding in the race to build more prison places. Others suspect that a lawyerdominated Ministry will only let out the offenders the police have caught. What is clear, however, is that there is an opportunity for some agencies to take a step back and rethink the way in which they operate.

It is clear that public protection arrangements will continue to straddle the two departments but there has been something of a symbolic break. Probation staff may be able to take advantage of Juliet Lyon's hope for a refocused service. At the same time, it is to be hoped that the police service does not retreat to old ways under its reemphasised security mantle. The polibation officer may indeed have been decoupled and this may not be such a bad idea. The trick will be for the two main players, police and probation services, to focus on what they do best and bring both these experiences to the MAPPA table.

\section{References}

(ACOP) Association of Chief Officers of Probation. (1988). More Demanding than Prison: Wakefield: author.

Barnardo's. (2006). A risk too high? Would public disclosure (Sarah's Law) protect children from sex offenders? Retrieved December 20, 2006 from http://www.barnardos.org.uk/a_risk_ too_high_public_disclosure_report.pdf.

Bentley, D. (2007, March 29). Blair unveils new justice ministry. The Independent.

Bottoms, A. (1977). Reflections on the Renaissance of Dangerousness. Howard Journal of Criminal Justice, 16, 70-96.

Bridges, A. (2006). Working with dangerous offenders: What is achievable? Unpublished paper, University of London, School of Oriental and African Studies.

Cabinet Office. (2007a). Machinery of Government: Security and Counter-Terrorism, and the Criminal Justice System Issues (Cabinet Office Report). London: HM Government.

Cabinet Office. (2007b). Building on progress: Security, crime and justice. London: HM Government.

Cavadino, M., \& Dignan, J. (1997). The Penal System: An Introduction (2nd ed.). London: Sage.

Corrigan, R. (2006). Making Meaning of Megan's Law. Law and Social Inquiry, 31(2), 267-312.

Garland, D. (2001). The Culture of Control, Oxford: Oxford University Press.

HMIP (HM Inspectorate of Probation). (2006). An Independent Review of a Serious Further Offence case: Anthony Rice. London: author.

Home Office. (2006a). Working together to reduce reoffending. Improving Prison and Probation Service Public Value Partnerships. London: National Offender Management Service (NOMS).

Home Office. (2006b). Restructuring probation to reduce reoffending. London: National Offender Management Service (NOMS).

Kemshall, H. (2003). Understanding risk in criminal justice. Maidenhead: Open University Press.

Kemshall, H., \& Maguire, M. (2001). Public protection, partnership and risk penality: The multi-agency risk management of sexual and violent offenders. Punishment $\mathcal{E}$ Society, 3(2) 237-264.

Kershaw, C., Dowdeswell, P., \& Goodman, J. (1997, January). Life licensees reconvictions and recalls by the end of 1995: England and Wales. Research Findings, 2.

Madden, A. (2007). Treating Violence: A guide to risk management in mental health. Oxford: Oxford University Press.

Mawby, R.C., Crawley, P., \& Wright, A. (2007). Beyond 'polibation' and towards 'prisi-polibation'? Joint agency offender 
management in the context of the Street Crime Initiative. International Journal of Police Science and Management, 9(2), 122-134.

Mawby, R.C., \& Worrall, A. (2004).

'Polibation' revisited: policing, probation and prolific offender projects. International Journal of Police Science and Management, 6(2), 63-73.

Mitchell, B. (2007). Justice Ministry's welcome marred by political fallout. Legalweek.com. Retrieved April 5, 2007 from http://www. legalweek.cpm/Articles/1020270/Justice+ ministry5E.

Nash, M. (1999). Enter the Polibation Officer. International Journal of Police Science and Management, 1(4), 252-261.

Nash, M. (2004). Polibation revisited - a reply to Mawby and Worrall. International Journal of Police Science and Management, 6(2), 74-76.

Parole Board for England and Wales. (2006). Annual Report and Accounts, 2005-6. London: author.
Prins, H. (1988). Dangerous Clients: Further Observations on the Limitation of Mayhem. British Journal of Social Work, 18, 593-609.

Rozenberg, J. (2007, April 12). Law: Yes Minister, I am suspicious. Daily Telegraph.

Scott, J., Grange, T., \& Robson, T. (2007). MAPPA - The First Five Years: A National Overview of the Multi-Agency Public Protection Arrangements 2001-2006. London: Home Office.

Sheldrick, S. (1999). Practitioner review: The assessment and management of risk in adolescents. Journal of Child Psychology and Psychiatry, 40(4), 507-518.

Tempest, M. (2007, March 29). Home Office to be split in two. The Guardian.

Vanstone, M. (2004). Mission control: The origins of a humanitarian service. Probation Journal, 31(1), 34-47.

Wright, A. (2000). Managing the future: an academic's view. In F. Leishman, B. Loveday, \& S. Savage (Eds.), Core Issues in Policing (pp. 288-304). (2nd edn.) Harlow: Pearson Education. 